\title{
Pedagogical Innovation versus Technological Innovation: Curricular Tensions
}

http://dx.doi.org/10.3991/ijes.v2i1.3672

Alaim Souza Neto, Universidade do Estado de Santa Catarina, Florianópolis, SC, Brasil

Geovana Mendonça Lunardi Mendes, Universidade do Estado de Santa Catarina, Florianópolis, SC, Brasil

Abstract - this article aims to investigate the forms of pedagogical appropriation of MUV 3D laptops available in the public schools of Santa Catarina from PROUCA Program, since research conducted mainly in the last 10 years (VALENTE, 2003, 2008; ALMEIDA, 2004; FAGUNDES, 2005; SANCHO and HERNANDEZ, 2006; GVIRTZ and LARRONDO, 2007), indicate that there is a lack of guidance on how to use the equipment. The problematic of this paper focuses on the discussion and understanding on how these technological artifacts can be applied to the schools by means of the use of 3D Virtual Worlds - 3D MUV - as digital platforms and how they impact the daily school and the curricular frameworks. Partial results of an ongoing research between the years 20112013, entitled "Are Lessons Interconnected? Curricular change and collaborative learning between schools of IICA project in Santa Catarina.

\section{Inovação pedagógica x Inovação Tecnológica: Tensões Curriculares}

\author{
Alaim Souza Neto e Geovana Mendonça Lunardi Mendes \\ Universidade do Estado de Santa Catarina, Florianópolis, SC, Brasil.
}

\begin{abstract}
Resumo-Este artigo tem como proposta investigar as formas de apropriação pedagógica dos MUV 3D nos laptops disponibilizados em escolas públicas de Santa Catarina a partir do Programa PROUCA, visto que pesquisas realizadas, principalmente nos últimos 10 anos (VALENTE, 2003, 2008; ALMEIDA, 2004; FAGUNDES, 2005; SANCHO E HERNANDEZ, 2006; GVIRTZ e LARRONDO, 2007), apontam que há falta de orientações sobre o que fazer com os computadores que chegam às escolas. A problemática deste artigo se concentra na discussão e compreensão de como esses artefatos tecnológicos se estabelecem na escola a partir do uso dos Mundos Virtuais 3D - MUV 3D - como plataformas digitais na lógica 1:1 e como eles impactam no cotidiano escolar e nas estruturas curriculares da escola e da sala de aula. São apresentados os resultados parciais de uma pesquisa em andamento entre os anos 2011-2013, intitulada "Aulas Conectadas? Mudanças curriculares e aprendizagem colaborativa entre escolas do projeto UCA em Santa Catarina.
\end{abstract}

Palavras-chave-Mundos Virtuais 3D, inovação pedagógica e tecnológica, estruturas curriculares.

\section{INTRODUÇÃO}

Com o grande advento da internet de forma potencializada a partir do início desse século, rapidamente, saímos da passividade frente à tela da TV nos anos 1950/1960, e nos deparamos com os anos 2000 em que as crianças nascem imersas num mundo digital. No cenário de educação a distância no Brasil surge uma tendência e perspectiva para a educação online que marca territórios e preferências. Isso pode ser observado nos dados do Censo EaD do ano de 2010, os quais mostram claramente que o modo síncrono de aprendizagem já está quase ultrapassando o modo assíncrono para utilização de artefatos tecnológicos nas instituições [1]. Não muito diferente, é a expressividade do número de pessoas no mundo que estão conectadas às redes sociais na internet.
Nesse contexto, o contato social se desterritorializa, a expressão corporal passa a ficar ausente e limitada, e ain$\mathrm{da}$, o meio online assume diversas versões, tanto na escola como fora dela. Particularmente na escola, as demandas pedagógicas se encontram também em busca de novos métodos de ensino e aprendizagem frente à geração de alunos "plugados", tentando se conectar ao mundo digital que já está disponibilizado na sociedade. Nesse sentido, vários são os autores na área de educação que já nos alertaram para a inserção de tecnologias digitais nos processos educativos como uma necessidade cada vez mais exigida $[2,6]$.

Os desdobramentos desse mundo digital na escola desestabilizam as relações entre professores e educandos com o tempo, o espaço e, principalmente, os saberes pedagógicos, propriamente os conteúdos curriculares, prescritos na lógica tradicional da escola como fonte única de acesso ao conhecimento poderoso de que Young [7] nos fala. Como afirma Dussel "estamos diante de mudanças de natureza profunda nas verdades e estruturas que sustentam as práticas escolares" [8]. Utilizar os novos artefatos em todas as suas potencialidades significa questionar o modelo comunicacional presente em sala de aula, os regimes de verdade por meio dos quais a escola organiza e distribui o conhecimento produzido e também as formas de produção de conhecimentos, entre outras questões relevantes.

Apresentamos este artigo, dada a sua relevância ao momento vivido no contexto educacional brasileiro, no qual se encontra em expansão a inserção de novos artefatos culturais na educação em diferentes níveis, bem como as ofertas de ensino na modalidade "a distância". Este fato tem exigido se repensar os currículos escolares a fim de que possamos propiciar uma educação para esse tempo histórico e social, formando homens e mulheres de seu tempo, como propunha Freire [9], o que significa na atualidade também educar para emancipação digital cidadã. Em outras palavras, Lunardi Mendes, Correa e Borges 
[10] apud Sancho [11], afirmam que parece que estamos diante de uma espécie de "cavalo de tróia", ou seja, a crença que somente a inserção das tecnologias no contexto escolar provocará mudanças nas práticas e no currículo.

Delimitando melhor o objeto deste artigo, esclarecemos que nossa proposta é investigar as formas de apropriação pedagógica dos MUV 3D nos laptops disponibilizados em escolas públicas de Santa Catarina a partir do Programa PROUCA, visto que pesquisas realizadas, principalmente nos últimos 10 anos [12,14], apontam que há falta de orientações sobre o que fazer com os computadores que chegam às escolas. Nesses estudos e tantos outros, fica claro que a evolução das tecnologias tem um importante papel na globalização, provocando mudanças nos modos de ser e estar no mundo, reconfigurando as relações comunicacionais e fazendo surgir novas ordens sociais, denominadas de: sociedade tecnológica, sociedade em rede, sociedade da informação, sociedade do conhecimento, sociedade cognitiva, sociedade digital e muitas outras ainda.

Mais precisamente, queremos descrever os resultados parciais de uma pesquisa em andamento entre os anos 2011-2013, intitulada "Aulas Conectadas? Mudanças curriculares e aprendizagem colaborativa entre escolas do projeto UCA em Santa Catarina. A questão central para nós não será mais a adesão ou não às novas tecnologias nos processos educativos, e muito menos, a promoção ou não ao acesso aos dispositivos tecnológicos disponíveis. A problemática deste artigo se concentra na discussão e compreensão de como esses artefatos tecnológicos se estabelecem na escola a partir do uso dos Mundos Virtuais 3D - MUV 3D - como plataformas digitais na lógica 1:1 e como eles impactam no cotidiano escolar e nas estruturas curriculares da escola e da sala de aula. Ou seja, a intenção é tornar público como os MUVs 3D foram recebidos pelos educandos durante as práticas escolares, atentando para elementos didático-pedagógicos que revelam uma possibilidade de termos no contexto escolar, inovações pedagógicas curriculares durante os processos de ensino e aprendizagem que se sobrepõem às meras inovações tecnológicas, bem como descortinar práticas pedagógicas da escola que possam ser utilizadas, tendo como base novas concepções de educação, currículo e inovação. Não a inovação que procura enfatizar a questão das experiências dos alunos, bem como seus interesses e contextos, mas sim a inovação que privilegie o conhecimento científico [18].

Entendemos que o uso dos artefatos culturais tecnológicos podem potencializar o processo de ensino e aprendizagem como transformadores e produtores de novos conhecimentos com vistas à inclusão digital, pois esses artefatos podem estruturar o pensamento, o modo de ser, estar e de se relacionar no e com o mundo. Nesse sentido, em relação às mídias e tecnologias, elas podem ser utilizadas como estruturantes para novos currículos escolares [42].

Para melhor compreender o objeto Mundos Virtuais 3D no currículo escolar, também apresentamos os seus conceitos, sua origem e história, suas aplicações e seus primeiros desdobramentos na educação, particularmente na sua aplicação na escola com crianças e adolescentes.

\section{CURRÍCULO E TECNOLOGIAS}

Na contemporaneidade, de diferentes formas, vários são os países que tecnologicamente avançados ou em desenvolvimento, lançaram projetos e políticas de mudanças tecnológicas para as práticas escolares. Conforme Sancho [11], tivemos primeiramente a informática educativa, depois as TIC aplicadas à educação e atualmente projetos como e-learning, m-learning e u-learning. Tais projetos e políticas demandam melhorias nos processos de ensino e aprendizagem dos alunos, bem como reformas nas formas de organização escolar. São posturas que os responsáveis pelas políticas públicas precisam tomar ciência, pois só a presença de tecnologias nas escolas não garante resultados satisfatórios na melhoria da aprendizagem e no desenvolvimento do currículo $[5,15,16]$.

No que se refere à organização escolar, recorremos a Almeida [17], a qual nos apresenta uma primeira compreensão para o conceito de currículo que se sustenta na compreensão da organização e da construção do conhecimento na ação de aprender. Para a autora, "[...] o currículo será construído no próprio desenvolvimento da formação, se orientará pelas pesquisas e para a pesquisa, o que valoriza a postura problematizadora por parte de formadores e de formados" [17].

É nossa intenção, problematizar essa e outras concepções de currículo que possam se relacionar ao uso das tecnologias no espaço escolar. Contudo, para compreender a relação entre currículo e tecnologias e suas relações na sala de aula, precisamos primeiramente compreender a concepção de currículo, tomando como referência o seu ambiente de privilégio: o contexto escolar. Para isso, buscamos em Young [7] uma resposta para a pergunta: "para que servem as escolas?". Para o autor, essa questão significa perguntar "[...] como e por que as escolas emergiram historicamente, em tempos e sociedades diferentes, como instituições específicas, com o propósito específico de capacitar alunos a adquirir conhecimento não disponível em casa ou no seu cotidiano" [7]. Para o autor, o currículo precisa considerar o conhecimento local e cotidiano que os alunos trazem à escola, contudo esse conhecimento não deverá ser a referência para a construção do currículo. Ele também defende que a educação na sociedade do conhecimento precisa ter um currículo organizado a partir das necessidades de aprendizagem, ou seja, um currículo que privilegie o conhecimento e diverso do modelo tradicional de currículo para submissão.

Acrescenta, ainda, que o conhecimento local é estruturado de forma a relacionar-se com o particular e não poderá ser a base dos princípios generalizáveis. Essa seria a razão pela qual todos os países têm escolas, e por isso, a necessidade de se diferenciar o conhecimento escolar e não-escolar. Para Young [18], fica claro que os educandos não vão à escola para aprender sobre suas experiências, mas para se apropriar de conhecimentos gerados pelas pesquisas e pela comunidade científica. Ele ainda destaca que esse tipo de conhecimento é que dá sentido à escola e confiabilidade ao currículo, visto que a escola é um lugar em que se dá a transmissão do conhecimento e do poder e o mundo aparece como objeto de reflexão. Segundo Lunardi Mendes [19],

No fundo, a possibilidade de dispor de um enorme arquivo de cultura, como nunca antes disponível, e também a possibilidade de participar de processos de construção coletiva de conhecimento, evidenciam a necessidade curricular de discutir a própria validade do conhecimento escolar que está sendo ensinado e torna urgente o trabalho da escola com o que Young [7] chama de conhecimento poderoso, ou seja, um conhecimento de qualidade cien- 
tifica muitas vezes inacessivel em outros ambientes por crianças que vivem em condições sociais desfavorecidas.

Feita a reflexão sobre o papel da escola, resta ao professor compreender a sua função enquanto educador no desenvolvimento do currículo, refletindo continuamente sobre várias questões norteadoras da sua prática: "o que, como, para quê, para quem, a favor de quem" se estrutura o processo de ensino e aprendizagem de modo a conduzir os educandos à "reconstrução do saber ensinado" [9].

Neste artigo, cabe-nos ainda desmistificar algumas concepções de currículo que rondam o contexto educacional. Nessa empreitada, o conceito de currículo nos exige uma tomada de decisão frente aos vários discursos e visões sobre o assunto dada a polissemia do termo. Em primeira consulta ao Dicionário Houaiss, o termo "currículo" é uma expressão que tem sua origem no latim curriculum, que significa "corrida", "carreira", "lugar onde se corre", "campo", "liça", "hipódromo" e "picadeiro", e ainda, do verbo em latim currere, que significa "correr", "curso". De saída, já percebemos de forma ingênua que a concepção de currículo diz respeito a um percurso ou trajetória de um curso, algo muito além das listas de conteúdos, temas de estudo ou unidades de ensino, extrapolando em muito as prescrições curriculares e envolvendo todo o lugar e o tempo em que ele se desenvolve [20].

Lexicamente, Pacheco [21] contrapõe duas noções implícitas de na concepção de currículo: "uma sequência ordenada, outra de noção de totalidade de estudos [...]. O currículo é uma prática pedagógica que resulta da interação e confluência de várias estruturas na base das quais existem interesses concretos e responsabilidades compartilhadas". Michael Apple [22] acrescenta que o currículo ainda precisa se caracterizar como um processo de reconstrução em um ambiente de representações técnicas, estéticas, éticas, políticas e ideológicas, segundo uma "tradição seletiva" do que é considerado "conhecimento legítimo". Para dar mais peso a essa concepção de currículo, adotaremos conceitos do campo curricular de três grandes teóricos: Ivor Goodson, Antônio Flávio Moreira e Michael Young.

Primeiramente, para Goodson [23], o conceito de currículo é compreendido como uma construção social que se desenvolve na interação dialógica entre escola, vida, conhecimento e cultura, produzindo os mais diferentes percursos. Dessa forma, o currículo acaba por integrar os conteúdos da cultura selecionados criteriosamente de acordo com determinadas intenções para uso nos processos de ensino e aprendizagem, com as múltiplas concepções, valores, ideologias, experiências, tecnologias e estratégias sendo mobilizadas para a realização do contexto pedagógico.

Assim, o currículo não pode ser compreendido como a aplicação e transferência do conteúdo prescrito em documentos referenciados pelas mais diversas instituições, livros didáticos, planos de ação, sistemas de ensino e portais educativos, posteriormente sendo repassado aos educandos no contexto da sala de aula. Pelo contrário, ele precisa se desenvolver na reconstrução desse conteúdo prescrito nos processos de representação de significados e negociação de sentidos que ocorrem, primeiramente, no momento em que os professores planejam a condução de suas disciplinas, considerando as características do seu contexto de sala de aula, as potencialidades e necessidades dos seus educandos, bem como suas preferências e sua forma de conduzir a prática pedagógica. Assim, teremos um currículo ressignificado no momento da ação pedagógica [20].

Em seguida, para Moreira e outros [24], o desenvolvimento curricular não pode ser restrito aos conteúdos prescritos em grades que se estabelecem pelas disciplinas curriculares, e muito menos aos conhecimentos que relacionam as experiências e conhecimentos dos educandos sobre seu cotidiano. Concordamos com os autores, por achar fundamental diferenciar um currículo que parte da experiência e conhecimento do senso comum daquele que se constrói em torno da experiência e da aplicação do conhecimento à realidade cotidiana do educando. Afirmamos isso a partir da ideia de "[...] que o conhecimento formal traz outras dimensões ao desenvolvimento humano, além do "uso prático" e somos defensores da ideia de uma metodologia que parte da "experiência cultural do aluno como caminho para ampliação da experiência humana na escola" [24].

Essa concepção não nega a disciplina e o conteúdo curricular, contudo necessita identificar a estrutura lógica de cada área do conhecimento, revendo a concepção de disciplina e sua função na escolarização de modo a transformá-la em algo flexível que inclua o conhecimento do senso comum que o educando traz de sua realidade. Nesse processo, o professor precisa dialogar com os educandos, despertando-lhes a curiosidade sobre os grandes eventos do mundo, problematizando sua realidade e propondo atividades em que explicitem o que já sabem sobre seu mundo, mas buscando novas informações que possam transportá-los do estágio do conhecimento do senso comum para um novo patamar do conhecimento, ampliado de possibilidades para compreender o seu mundo e de formalizar o conhecimento científico [20].

Nessa esteira de reflexões, resta-nos ainda acrescentar as contribuições de Young [18], as quais problematizam as inovações pedagógicas e curriculares, afirmando que temos um longo caminho pela frente a ser enfrentado no contexto educacional brasileiro. Contudo, precisamos a cada dia criar ou recriar novas alternativas para o currículo escolar, e por isso, a possibilidade de usar os Mundos Virtuais 3D no ambiente escolar, empreendendo esforços e pesquisas que possam equacionar as tensões e conflitos que se originam na constituição das diferentes lógicas de ensino e currículo. Na verdade, ficam nas palavras de Young [18] a necessidade contínua de uma prática sem fim e sem soluções absolutas e definitivas. Há que se estabelecer um processo dialético de pesquisa que sempre problematize como o currículo do futuro se estabelecerá no contexto educacional. Enfim, segundo Young [18]:

$A$ idéia de um "currículo do futuro" continua a ser isso mesmo - uma tendência e uma idéia que dificilmente encontramos em qualquer forma institucional. É inquestionável que ela ainda tem um longo caminho a percorrer no que respeita ao estabelecimento de uma base de confiança que demonstre que se tratará de uma maneira de promover aprendizagens de alta qualidade.

A partir da concepção que relaciona os teóricos que trouxemos à baila neste artigo, poderemos contemplar um currículo que vê nas tecnologias a possibilidade de deixar de ser centrado em conteúdos prescritos associados ao ensino por meio de métodos instrucionistas e baseado na distribuição de materiais didáticos em que pesem a digitalização e o uso do software para valorizar a lógica disci- 
plinar. Assim, conforme Almeida e Valente [20], podemos ver nas tecnologias uma potencialização da comunicação multidirecional, das representações do conhecimento por meio de distintas linguagens e do desenvolvimento de produções colaborativas com educandos localizados nos mais diversos lugares, tempos e contextos, superando a abordagem ancorada em princípios de racionalização e divisão do trabalho propostos por "Tyler" e "Bobbit" $[25,26]$ em prol de uma abordagem dialógica, polifônica, construtiva e histórico-social.

\section{MAS O QUE SÃO OS MUNDOS VIRTUAIS $3 \mathrm{D}$ ?}

Não se tem precisamente a origem para os MUVs 3D, pois atualmente eles estão sendo aplicados nos mais diversos setores socioeconômicos, e relacionados às variadas áreas do conhecimento. Nesse sentido suas origens podem remontar a três grandes vertentes: realidade virtual, chats e os jogos digitais. A primeira das três vertentes referendadas anteriormente, a realidade virtual, iniciou pela compreensão da:

[...] indústria de simulação, com os simuladores de vôo que a Força Aérea dos Estados Unidos passou a construir depois da Segunda Guerra Mundial. O termo originou-se nos anos 80, quando Jaron Lanier necessitou de um termo para diferenciar as simulações tradicionais por computação dos mundos digitais que ele tentava criar [27].

A segunda possibilidade de origem para os mundos virtuais 3D são os chats. Quem apresenta essa possibilidade é Raquel da Cunha Recuero em seu artigo intitulado Avatares - Viajantes entre Mundos, publicado em 2000. A autora descreve o conceito de chat como "[...] forma de interação proporcionada pela internet [...]" [28] e em seguida afirma que os chats têm uma evolução a partir dos computadores pessoais, informando que eles se apresentaram inicialmente "puramente textuais" e resumam-se às linhas comunicacionais escritas entre apenas duas pessoas por meio de mensagens simultâneas. Com o tempo o chat tomou uma dimensão maior e assumiu a forma de ambiente multiusuário.

Dentro desses ambientes multiusuários, surgiu o MUD (Multiple User Dungeon ou Multiple User Dimension), um programa de computador em que os usuários poderiam, além de enviar e receber mensagens em tempo real (ou quase real), explorar uma realidade que era construída textualmente, ou seja, um "mundo" virtual fantasioso criado por outros usuários [28].

Depois dessa possibilidade de origem para os mundos virtuais, Kamienski, Fernandes e Silva [29] apresentam uma terceira possibilidade para origem dos MUVs 3D: os jogos digitais. A essa possibilidade é que se fará maior referência neste artigo, visto essa origem apresentar características estreitamente relacionadas com a concepção de MUVs 3D e seus desdobramentos que estão sendo levados em conta para esta pesquisa.

Concebe-se o mundo virtual 3D como uma comunidade online que toma a forma de um ambiente tridimensional por computador por meio do qual os usuários podem interagir entre si, usando e criando novos objetos. Contudo, a fim de dar conta desse conceito de forma científica, será necessário discutir as diferentes concepções para os MUVs 3D.

A primeira delas tem sua origem no Projeto RexLab da UFSC, o qual compreende os mundos virtuais como uma metáfora de computação do próprio mundo real e esse contendo as pessoas, os lugares e os objetos, os quais poderão ser articulados como objetos de interação [30]. A segunda concepção, também integrante do projeto RexLab da UFSC tem-se que: "os mundos virtuais são uma metáfora do mundo real [...]" [31]. A terceira concepção é apresentada por Klastrup [32], o qual concebe o mundo virtual como:

'Mundo virtual' são mundos nos quais se pode navegar através de representações persistentes do usuário, ao contrário de mundos imaginados de ficções não-digitais, os quais são apresentados como habitados, mas não são realmente habitáveis. Mundos virtuais são diferentes de outros ambientes virtuais porque não podem ser imaginados em toda sua totalidade espacial [32].

Schlemmer e Backes [33] também concebem o mundo virtual como "[...] uma representação em 3D, modelada computacionalmente por meio de técnicas de computação gráfica e usado para representar a parte visual de um sistema de realidade virtual".

Em síntese, o importante dessas concepções dos mundos virtuais 3D descritas acima, é destacar que a maioria delas contempla em sua concepção características que são comuns entre si: imersão, interação e navegação. Na pesquisa de Tori, Kirner e Siscouto [34], caracterizam-se como mundos virtuais 3D aqueles que têm os seguintes aspectos: espaço partilhado, interface gráfica, imediaticidade, interatividade, persistência e socialização/comunidade.

Para compreender a nomenclatura a que pertencem os Mundos Virtuais, classificam-se eles em dois grandes grupos: o primeiro grupo, MMOG (Massively Multiplayer Online Game), contém os mundos virtuais classificados em três variações: MUD (Multi-User Dugeons), MMPORG (Massively Multiplayer Online Role Playing Game) e MMOFPS (Massively Multiplayer Online First Person Shooter). Esses três apresentam os jogos ambientados em cenários fictícios, com objetivos bem claros e com sistema de níveis para recompensar os usuários. $\mathrm{O}$ segundo grupo, MMOW (Massively Multiplayer Online World), contém os mundos virtuais que simulam a vida real, cujo principal objetivo é a interação social das pessoas por meio dos seus Avatares [29]. São aos MMOW que caracterizam os Mundos Virtuais 3D abordados neste artigo. Compreendida a nomenclatura, descreve-se a cronologia histórica que data a origem de cada um dos grupos e variações dos mundos virtuais.

Os primeiros mundos virtuais datam de 1960 e foram desenvolvidos para computadores de grande porte com objetivo de atender aos jogos baseados em conflitos e com regras pré-definidas [35]. Tem-se como registro do primeiro RPG (Role Playing Games) o Blackmoor, datado de 1970 em que "[...] os jogadores assumiam papéis de personagem e desenvolviam histórias de forma colaborativa" [36]. Em 1974, apareceria nos EUA um jogo de tabuleiro misturando ação e representação teatral, conhecido como "Dungeons \& Dragons". Esse, possivelmente, tenha sido o jogo que influenciou o surgimento dos primeiros mundos virtuais, os MUDs. Assim, surgiram os Multi-User Dugeons, chamado de MUD e criado em 1979 por Roy Trubshaw [29].

A partir de 1985 em diante, muitos dos mundos virtuais passaram a atingir sucesso comercial como parte do início dos serviços online. Assim nasceram os AberMUD, TinyMUD, LPMUD e DikuMUD, embora eles não tenham 
se viabilizado na plataforma para uso dos usuários comuns dada a falta de memória necessária e velocidade de processamento [36]. No início da década dos anos 1990 surgiram os jogos baseados em gráficos. Embora tenham existido exemplos de MMORPGs (Massively multiplayer online role-playing game) gráficos como o Oubliette (1977), Everwinter Nights (1991) e Shadows of Yserbius (1992), o Ultima Online foi considerado o primeiro MMORPG comercial de sucesso, tendo alcançando 100 mil usuários no fim do primeiro ano de lançamento. Os MMORPGs surgem a partir de Richard Garriott, criador do Ultima Online em 1997, o qual revolucionou a interface gráfica em relação aos antigos mundos virtuais [29].

Paralelamente, no final dos anos 90, o conceito de jogos online massivos para múltiplos jogadores, também se expandiu e novos gêneros de jogos surgiram, como por exemplo, os MMOFPS (Massively Multiplayer Online First Person Shooter). O primeiro jogo em rede 3D, na perspectiva de primeira pessoa (First Person Shooter), foi lançado em 1995 conhecido como Doom.

Em síntese, definem-se os mundos MMOG (Massively Multiplayer Online Games) em três categorias principais: MUD, MMORPG e MOFPS. Duas características principais são o alicerce dessa classificação, apresença de objetivos bem definidos com etapas e desafios e a grande quantidade de usuários interagindo em conjunto no mesmo ambiente.

Já na contemporaneidade, a concepção de mundos virtuais MMOW (Massively Multiplayer Online World) tem como características principais a capacidade de customizar e criar do mundo pelo próprio usuário, cujo objetivo fundamental é a interação social e permitir que praticamente qualquer atividade social do mundo real possa ser realizada. Dessa forma, os MMOW não são necessariamente jogos, e por isso, diferenciam-se dos ambientes MMOG [29].

Em resumo, pedagogicamente, os MMOWs diferenciam-se dos MMOGs, "[...] porque apesar de suportarem um grande número de usuários simultâneos, não apresentam ficção, níveis ou resultados quantificáveis" [37]. Nos MMOWs até é possível a construção de jogos, mas essa é apenas uma de suas possibilidades. Pode-se ainda citar o contraste da característica medieval, mística e ficcional de ambientes MMORGPs com os temas modernos e ambientes realistas dos MMOW [37].

OpenSim (OS), Second life (SL), Active Worlds (AW), Kaneva3, OpenColbalt4, ProtoTerra5 e Twinity6 são alguns exemplos dos MMOW disponíveis. Na atualidade, o OpenSim se apresenta como o mais interessante para a pesquisa, principalmente para a educação, dada a possibilidade de ser open source (aberto), e ainda pelos resultados em relação ao número impressionante de avatares conectados simultaneamente nas suas mais diversas aplicações [38].

Nos MUVs 3D não existem fronteiras para os alunos e professores, os conceitos de tempo e espaço são problematizados em relação à concepção da pedagogia tradicional, além de uma transformação completa nos processos de interação e colaboração, visto que a autoria e autonomia assumem outras dimensões. Nos MUVs 3D, tem-se a possibilidade, em tempo online, de se visitar vários espaços, conhecer outros aprendentes e desenvolver aprendizagens que não seriam possíveis presencialmente nas salas de aula.
Dentro de mundos virtuais é possível interagir com pessoas de diferentes partes do mundo, em tempo real, de uma forma extremamente dinâmica, através de estímulos auditivos e visuais que proporcionam um alto grau de imersão ao usuário, usando recursos gráficos $3 \mathrm{D}$, tecnologias como stream de vídeo e voz sobre IP[4], sendo assim, uma poderosa ferramenta que permite replicar situações comuns do mundo real, criando cenários onde é possível obter entretenimento, estudar, realizar pesquisas ou até mesmo trabalhar e ganhar dinheiro no mundo real [37].

\section{POSSIBILIDADES E LIMITAÇÕES DOS MUVS 3D}

A esperança de mudança para a educação por meio dos mundos virtuais proposta por Marcelino [31] é bem instigante para os pesquisadores que problematizam o processo de ensino-aprendizagem. Nesse sentido, muito importante é considerar quais aspectos estão sendo levados em conta pelo autor para afirmar tal mudança. Segundo Marcelino [31], vários são os motivos para incorporação desses no processo de ensino-aprendizagem dos alunos: maior motivação dos estudantes (usuários); o poder de ilustração da realidade virtual para alguns processos e objetos é muito maior do que outras mídias; permite uma análise de muito perto; permite uma análise de muito longe; permite que as pessoas deficientes realizem tarefas que de outra forma não são possíveis; dá oportunidades para experiências; permite que o aprendiz desenvolva o trabalho no seu próprio ritmo; não restringe o prosseguimento de experiências ao período da aula regular; permite que haja interação, e desta forma estimula a participação ativa do estudante [31].

Entre os recursos disponíveis nos mundos virtuais 3D, citam-se: a possibilidade de incluir recursos de voz para que todos os avatares possam se comunicar. Este já é um grande diferencial, pois a maioria dos ambientes virtuais não possui voz em tempo real, utilizando apenas dos chats, e consequente acabam não criando vínculos do aluno com o professor. Outra possibilidade está no elevado grau de imersão nos ambientes online, permitindo muita interação e colaboração a partir da sensação de presença real [39].

A interação e colaboração podem ainda serem fortalecidas entre os usuários dos mundos virtuais a partir da criação de avatares, conversas on-line, ambiente físico virtual $3 \mathrm{D}$ semelhante às salas de aula, além do contato visual e movimentação que o ambiente permite [40]. Dessa forma, os mundos virtuais $3 \mathrm{D}$ podem ser considerados como verdadeiras metáforas do mundo real, dada a possibilidade de as escolas, universidades e centros de treinamento ser comparados à realidade dos alunos, professores e sala de aula com a devida presença da mesa do professor e dos alunos [29].

Lévy [41] constata em suas pesquisas que as tecnologias educacionais podem exteriorizar e alterar as funções cognitivas humanas: a memória, a imaginação, a percepção e os raciocínios. A partir disso, pode-se pensar a aplicação dos mundos virtuais $3 \mathrm{D}$ como novas formas de acesso à informação, como a navegação hipertextual, acesso às informações por meio de programas de busca, exploração dos cenários contextuais, e muitas outras.

Segundo Azevedo [36], os mundos virtuais 3D são aplicáveis à educação, pois proporcionam; 
[...] a liberdade de autoria, comunicação, construção coletiva e distribuição da informação em massa, permite, também, a simulação de objetos do mundo real (realidade virtual) por meio de gráficos em alta resolução e scripts capazes de simular movimentos semelhantes aos que efetivamente ocorrem na nossa realidade. Ressalta-se que a Web tridimensional ainda se encontra nos primórdios e vem sendo denominada de Internet 3D [36].

No campo da educação, os MUVs 3D podem servir à educação formal (ensino fundamental, médio e superior), ao ensino de línguas estrangeiras, treinamentos das mais diferentes naturezas, bem como reuniões virtuais com os próprios professores. Além disso, poderá servir como auxílio ao ensino, completando uma metodologia presencial ou à distância. Enfatize-se a sua relevância à educação a distância $(\mathrm{EaD})$ devido ao alto grau de interatividade e colaboração por meio de vários recursos, como; chat, voz e vídeo em um só ambiente e em tempo real entre todos os usuários. Com os MUVs 3D, pode-se ir além até mesmo de uma criação online de uma sala de aula, criando objetos de aprendizagem em que o avatar pode interagir diretamente com tais objetos [37].

Com base nessas categorias possíveis para o processo de ensinoaprendizagem, esta pesquisa argumenta a favor da utilização dos mundos virtuais 3D como mais um dispositivo pedagógico para a educação formal e presencial, já que eles podem oportunizar outras dimensões de espaços de conhecimento, tornando-os mais emergentes e abertos a modelos curriculares lineares e práticas pedagógicas já ultrapassadas. Segundo kamienski, Fernandes e Silva [29], "[...] os atuais mundos virtuais possuem milhões de usuários cadastrados e permitem que milhares deles estejam conectados simultaneamente". Inclusive, algumas universidades brasileiras já estão fazendo uso dos mundos virtuais $3 \mathrm{D}$ em suas atividades presenciais e/ou à distância para apoio pedagógico em suas atividades presenciais [38].

\section{APLICAÇÕES DOS MUNDOS VIRTUAIS NA PRÁTICA PEDAGÓGICA}

$\mathrm{O}$ uso de tecnologias educacionais em ambientes em ambientes virtuais foi avaliada através da aplicação dos mundos virtuais 3D com crianças e adolescentes. Essa avaliação ocorreu por meio da apresentação de um ambiente 3D - Mundo Virtual, desenvolvido pelo Rexlab, para alunos e professores do Projeto Aulas Conectadas, realizado em parceria com a Universidade do Estado de Santa Catarina-UDESC e a Universidade Federal de Santa Catarine-UFSC [19].

A motivação científica desta pesquisa está em comunicar a primeira experiência prática de imersão de alunos e professores nos MUVs 3D aplicados como dispositivos pedagógicos levando em consideração os aspectos cognitivos e pedagógicos do processo de ensino e aprendizagem, como mais uma das muitas tentativas de se pensar possíveis alterações nas estruturas curriculares da educação formal como também problematizar o processo de ensinoaprendizagem.

O objetivo geral nessa fase do projeto de pesquisa é compreender quais são as primeiras contribuições ou limitações dos mundos virtuais 3D para o processo de ensino e aprendizagem online e como dispositivo pedagógico de interação, colaboração e cooperação.
Para esta pesquisa, tomou-se apenas o Open Simulator ou OpenSim utilizando o navegador Hippo Viewer como dispositivo, pois além de possuir um grande número de possibilidades técnicas em relação aos demais softwares servidores de mundos virtuais, ele é gratuito e de código aberto (open source) e, por último, aplicado na pesquisa investigativa que este artigo contempla.

Como instrumentos de coleta de dados utilizado para obter informações acerca dos grupos participantes foi utilizado um questionário aplicado aos alunos e professores. Dessa coleta, pretende-se analisar os dados com rigor a fim de verificar se existe a possibilidade de utilizá-los como proposta de se pensar a inovação e mudança curricular. O presente artigo busca contribuir para uma melhor utilização das tecnologias por parte de alunos e professores assim como o desenvolvimento de experiências sólidas quanto ao uso de tecnologias educacionais em ambientes virtuais $3 \mathrm{D}$.

Os resultados obtidos na aplicação dos mundos virtuais $3 \mathrm{D}$ são mostrados nas Figuras 1 e 2 . Como primeiros resultados, pode-se concluir que o nível de domínio e conhecimento de tecnologias educacionais se mostrou satisfatório para $75 \%$ dos alunos. Já com relação aos professores foi de $45 \%$. A primeira impressão ao entrar no mundo virtual foi boa para $100 \%$ dos alunos e $82 \%$ dos professores. Os resultados também mostraram que apenas $30 \%$ dos alunos encontraram alguma dificuldade, enquanto $75 \%$ dos professores encontraram dificuldades. Quanto à aplicabilidade em um contexto pedagógico, integralmente $100 \%$ dos alunos e professores afirmaram que o mundo virtual possui aplicação.

O que mais chamou a atenção no mundo virtual dentre os participantes foi à sua aplicabilidade educativa em que ambientes educativos com conteúdos de ciências e artes foram criados. Em seguida, foi a interação, seja com o ambiente e salas temáticas, tanto com os colegas conectados simultaneamente. Em terceiro lugar ficou a interface do programa que se apresentou de fácil manipulação e modelagem, e por último foi o acesso rápido que em alguns momentos foi prejudicado pela limitação do link e problemas de internet que impediram a conexão com o servidor.

A facilidade de interação com os objetos se deu de forma mais natural e rápida para os alunos, pois muitos pareciam já ter tido alguma experiência ou aproximação com esse tipo de ambiente. O mais provável talvez sejam a experiência e naturalidade com jogos digitais ou softwares que incorporam os mundos virtuais 3D. Quanto aos professores, eles apresentaram um pouco mais de dificuldade e alguns apresentaram um pouco de insegurança. Por fim, tanto os alunos como os professores, não gostaram no mundo virtual das dificuldades encontradas nos itens acima, como problemas de linguagem e acesso.

\section{CONSIDERAÇÕES FINAIS}

Em se tratando dos mundos virtuais $3 \mathrm{D}$, eles podem representar uma alternativa potencial face às novas gerações plugadas, já que são artefatos de alta inovação tecnológica e podem se tornar artefatos culturais de práticas inovadoras, podendo contribuir com o aperfeiçoamento dos processos de ensino e aprendizagem da contemporaneidade, embora ainda seja necessário para a sua aplicação, avançar nas discussões que tratam da estrutura tecnológica, do 
processo de formação de professores, e muito mais, do próprio processo de ensino e aprendizagem.

A pesquisa envolvendo os mundos virtuais $3 \mathrm{D}$ representa, sem dúvida, mais um avanço para a área educacional, a qual busca alternativas para a melhoria dos seus processos pedagógicos. Nas respostas escritas pela turma piloto foi observada a motivação da turma em conhecer, imergir e adentrar os mundos virtuais 3D no âmbito escolar, dada à possibilidade de imersão dos sujeitos e a posterior construção de seu próprio ambiente de aprendizagem. Este resultado encoraja os pesquisadores a realizar outras pesquisas, aplicando-os nas mais diferentes áreas do conhecimento, inclusive possibilitando-os aos educandos com necessidades especiais terem acesso ao conhecimento educacional sem sair de casa.

Essa experiência trouxe aos participantes novos olhares quanto ao uso das tecnologias em sala de aula. Os relatos de professores e educandos firmam a necessidade de se investir em ambientes similares para suprir as lacunas existentes hoje em sala de aula e tornar esse acesso às tecnologias presente também no contexto educativo. Muitas foram as contribuições dos professores e educandos que deixaram explícitos suas expectativas para acessos futuros.

Quanto a um final sobre o uso dos Mundos Virtuais 3D no contexto escolar, todos demonstraram a necessidade de um ambiente totalmente em português, com possibilidades para construção de novos espaços sob autoria dos próprios usuários e com a possibilidade de construção de salas temáticas que reproduzissem situações pedagógicas e curriculares tradicionais do seu cotidiano, como: a teoria do Big-Bang, a História do Brasil, a História Natural, os museus de fósseis. Percebe-se a necessidade de construção de ambientes diferenciados do contexto contemporâneo, como o centro da terra, mundo subaquático, planetas do sistema solar, ambientes que pudessem ser utilizados, inclusive, por portadores de deficiências.

Em se tratando do campo curricular, a pesquisa foi feita a partir de distintos olhares e tem haver com a necessidade de recorrência de diálogos sobre a relação currículo e tecnologias na contemporaneidade. Em especial, de uma profunda reflexão sobre os saberes e fazeres no âmbito das intervenções pedagógicas em que cada uma das concepções de currículo descritas neste artigo, procura deixar claro que o currículo não se restringe à concepções prescritivas em seu processo e nem mesmo quanto às aplicações que delas derivam. Antes, o seu caráter educativo solicita intervenções permanentes e aproximadas da definição do próprio homem: um ser em movimento e transformação.

\section{REFERÊNCIAS}

[1] ABED, “Censo EaD.BR 2010," São Paulo: Pearson, 2012.

[2] J. Steven, "Tudo que é ruim é bom para você: como os games e a TV nos tornam mais inteligentes," Rio de Janeiro: Zahar, 2012.

[3] S. Paula, "Redes ou paredes: a escola em tempos de dispersão," Rio de Janeiro: Contraponto, 2012.

[4] P. Marc, "Não me atrapalhe, mãe - Eu estou aprendendo!: como videogames estão preparando nossos filhos para o sucesso no século XXI: e como você pode ajudar!," São Paulo: Phorte Editora, 2010.

[5] S. Fernando César, L. M. Geovana Mendonça e P. José Augusto, "Currículo e novas tecnologias em tempos de globalização," Perspectiva (UFSC), vol. 27, p. 19-46, 2009.
[6] F. Monica, "Mídia-Educação: conceitos, experiências, diálogos Brasil-Itália," Florianópolis: Cidade Futura, 2006.

[7] Y. Michael, "Para que servem as escolas? Educação e Sociedade," Rio de Janeiro, vol. 28, n. 1001, p. 1279-1282, set/dez. 2007.

[8] D. Inés, "VII Foro Latinoamericano de Educación: aprender y enseñar en la cultura digital". Buenos Aires: Santillana, 2011.

[9] F. Paulo, "Pedagogia da autonomia: saberes necessários à prática educativa," 14. ed. São Paulo: Paz e Terra, 1996.

[10] L. M. Geovana Mendonça, C., Juan Casanova e B. Martha Kaschny, "Entrevista com a Professora Doutora Juana María Sancho," Revista Linhas, Espanha, Universidade de Barcelona, p. 03-14, 2009.

[11] S. Juana Maria, "Tecnologias digitais, formação de professores e contextos escolares: novos desafios, velhos problemas," Entrevistafeita por: L. M. Geovana Mendonça, C. Juan Casanova e B. Martha Kaschny In: L. M. Geovana Mendonça e B. Martha Kaschny (Orgs.). Dossiê Revista Linhas: Educação, Comunicação e Tecnologia em debate. 2. ed. Florianópolis: UDESC, 2009. v. 10.

[12] F. Léa da Cruz e B. Marcos Vinícius de Azevedo, Mídias digitais, sistemas de conceitos e aprendizagem em matemática. Revista Brasileira de Informática na Educação, vol. 13, n. 2, p. 42-52, 2005.

[13] S. Juan Maria e H. Fernando (Org.), "Tecnologias para Transformar a Educação," Porto Alegre: Artmed, 2006.

[14] G. Silvina e L. Marina, "Notas sobre la escolarización de la cultura material, Celulares y computadoras en la escuela de hoy," Revista TEIAS: Rio de Janeiro, ano 8, n. 15-16, jan/dez. 2007.

[15] A. Maria Elizabeth Bianconcini, "Tecnologias na educação: dos caminhos trilhados aos atuais desafios," BOLEMA - Boletim de educação Matemática, UNESP, Rio Claro, 2008.

[16] V. José Armando e A. Fernando José de, "Visão analítica da informática no Brasil: a questão da formação do professor," Revista Brasileira de Informática na educação, Sociedade Barsileira de Computação, Florianópolis, n. 1, 1997.

[17] A. Maria Elizabeth Bianconcicni, "Informática e Formação de professores," Brasília: Ministério da Educação, 2000. v. 2. Disponível em: <http://www.scribd.com/doc/26138566/Livro09Elizabeth-Almeida\#fullscreen:on>. Acesso em: 10 maio 2013.

[18] Y. Michael, "Conhecimento e currículo: do socioconstrutivismo ao realismo social na sociologia da educação," Tradução de Jorge Ávila de Lima. Porto: Porto Editora, 2010.

[19] L. M. Geovana Mendonça (Coord.), "Aulas Conectadas? Mudanças Curriculares e Aprendizagem Colaborativa entre as Escolas do Projeto UCA em Santa Catarina," Projeto de Pesquisa apresentado ao $\mathrm{CNPq}$ para solicitação de Auxílio à Pesquisa - Edital CNPq/Capes/SEED-MEC n. 76/2010, Florianópolis, 2011.

[20] A. Maria Elizabeth Bianconcini e V. José Armando, Tecnologias e currículo: trajetórias convergentes ou divergentes? São Paulo: Paulus, 2011.

[21] P. José Augusto, Currículo: teoria e práxis. Porto: Porto Editora, 1996.

[22] A. Michael, Repensando ideologia e currículo. In: M. Antonio Flávio e S. Tomaz Tadeu da. (Orgs), Currículo, cultura e sociedade. São Paulo: Cortez, 1994.

[23] G. Ivor, As políticas de currículo e de escolarização. Abordagens históricas. Petrópolis, RJ: Vozes, 2006.

[24] M. Antonio Flávio e S. Tomaz Tadeu da (Orgs), Currículo, cultura e sociedade. São Paulo: Cortez, 1994.

[25] K. Herbert M, Burocracia e Teoria do Currículo. Currículo sem Fronteiras, v. 11, n. 2, p. 5-22, jul./dez. 2011.

[26] K. Herbert M, Os Princípios de Tyler. Currículo sem Fronteiras, v. 11, n. 2, p. 23-35, jul./dez. 2011.

[27] D. Jeferson, "O Mundo Virtual como Ferramenta Interativa no Processo de Ensino-Aprendizagem Colaborativo," Dissertação (Mestrado em Educação)- Pontifícia Universidade Católica do Paraná, Curitiba, 2003.

[28] R. Raquel Cunha, "Avatares: Viajantes entre mundo," Disponível em: $<$ http://www.pontomidia.com.br/raquel /avatares.htm>. Acesso em: 10 mar. 2012.

[29] K. Carlos Alberto, F. Stênio Flávio de Lacerda e S. Cledja Karina Rolim da, "Mundos Virtuais: Histórico, Avaliação e Perspectivas," 2008. Disponível em: <http://nupro.ufabc.edu.br 
/gtmv/wiki/images/3/3b/Webmedia2008_minicurso4_mundos_virt uais.pdf.>. Acesso em: 12 fev. 2013.

[30] S. Juarez Bento da, A utilização da experimentação remota como suporte a ambientes colaborativos de aprendizagem. Tese (Doutorado no Programa de Pós Graduação em Engenharia e Gestão do Conhecimento)- Universidade Federal de Santa Catarina, Florianópolis, 2006.

[31] M. Roderval, “Ambiente Virtual de Aprendizagem Integrado a Mundo Virtual 3d e a Experimento Remoto Aplicados ao Tema Resistência dos Materiais," 2010. 125 f. tese (Doutorado) - Programa de Pós-Graduação em Engenharia de Minas, Metalúrgica e de Materiais-PPGE3M, UFRGS, 2010.

[32] K. Lisbeth, Towards a poetics of virtual worlds. Multi-user textuality and the emergence of story 2003. Tese (Doutorado) IT University of Copenhagen. Copenhague.

[33] S. Eliane e B. Luciana, Metaversos: novos espaços para construção do conhecimento. Revista Diálogo Educativo, vol. 8, n. 24, p. 519532, 2008.

[34] T. Romero, K. Claudio e S. Robson, Fundamentos e tecnologia de realidade virtual e aumentada. VIII Symposiun on Virtual Reality, 2010. Disponível em: <http://www.gamecultura.com.br /downloads/livros/livrosvr2006-final.pdf >. Acesso em: 15 maio 2012.

[35] S. Katie e Z. Eric, Rules of play: game design fundamentals. Cambridge: MIT Press, 2003.

[36] A. Carlos Eduardo Ferrão, Proposta de uma Aplicação de Mundos Virtuais com Focos Tecnológico, Social e Educacional. Tese (Doutorado no Programa de Pós-Graduação em Informação)- Universidade Federal de Santa Catarina, Florianópolis, 2011.

[37] S. Marcelo Anderson Batista dos, SIMP2P: Uma estratégia P2P de distribuição de texturas em Mundos Virtuais 3D. 2011. Dissertação
(Mestrado em Engenharia da Informação)- Universidade Federal do ABC, São Paulo, 2011.

[38] S. Ana Cristina Rodrigues da e F. Neusa Rodrigues, Avaliação do uso de mundos virtuais como apoio ao processo de ensino e aprendizagem de projeto. Revista educação gráfica, vol. 15, n. 01, p. 0620, 2011.

[39] V. Carlos e M. João, "Second Life e Web 2.0 na Educação: o potencial revolucionário das novas tecnologias," São Paulo: Editora NovaTec, 2007.

[40] T. Romero, "A presença das tecnologias interativas na educação," RECET, vol. 2, n. 1, 2010. Disponível em:

[41] <http://revistas.pucsp.br/index.php/ReCET/article/view/3850/2514 >. Acesso em: 20 fev. 2013.

[42] L. Pierre, O que é o virtual? São Paulo: Ed. 34, 1996.

[43] A, Maria Elizabeth Bianconcini de, Integração de tecnologias às práticas escolares e ao currículo. In: $10^{\mathrm{a}}$ JORNATEC: Jornada Catarinense de tecnologia educacional, Anais... Florianópolis: SESC/SC, 2013.

\section{AUTORES}

Alaim Souza Neto - UDESC e UFSC. Rua Irmãos Vieira, 221, bloco A - Ap 1105 - Campinas - São José - SC - CEP 88101-290. Email: alaimsatc@yahoo.com.br.

Geovana Mendonça Lunardi Mendes - UDESC. Rua Maestro Aldo Krieger, 108, apto 905, Córrego Grande, Florianópolis, SC - CEP 88037-500. Email: geolunardi@gmail.com.

Submitted 19 March 2014. Published as re-submitted by the authors 05 April 2014. 